\title{
INTELLECTUAL IMPAIRMENT IN MUSCULAR DYSTROPHY
}

\author{
BY \\ VICTOR DUBOWITZ \\ From the Department of Child Health, University of Sheffield
}

(RECEIVED FOR PUBLICATION AUGUST 7, 1964)

The association of intellectual retardation with childhood muscular dystrophy was noted many years ago. Duchenne (1872) thought that 5 of his 13 cases were retarded. Gowers (1879), on the other hand, found evidence of mental retardation in only 2 of his 24 patients, and he thought that it was not a feature of the muscle disease but that there was probably a higher incidence of muscular dystrophy in mentally retarded children. In Erb's (1891) review of 83 cases of muscular dystrophy there are 25 whose case histories conform to the Duchenne-type: mental retardation was recorded in 5 of these, the intelligence was said to be normal in 7 , and there was no comment about the others.

In recent years there has been some controversy about the presence of intellectual impairment in muscular dystrophy. Walton and Nattrass (1954) studied 48 cases of Duchenne-type muscular dystrophy and concluded that, in spite of clinical impressions, no patient was mentally defective and only four were slightly backward. They thought that this clinical impression of backwardness could be attributed to loss of education, or to the reaction of these patients to their physical disability. Truitt (1955) also concluded that the mental ability of a series of patients with pseudohypertrophic muscular dystrophy was 'within the limits of normal expectation for the socio-economic group', that it was commensurate with the intelligence of their sibs, and that it did not decrease with advanced age or progression of the disease.

On the basis of the verbal part of the Wechsler Intelligence Scale for children, Morrow and Cohen (1954), in a study of 29 cases, found a mean IQ of 94. Although this was below average, they concluded, on the basis of other psychological data, that the lowered intellectual functioning resulted from the social and educational consequences of the disease and was not a primary consequence of the muscular dystrophy. They also found that in schooling about one-half of the patients were in grades one or more years behind other children of the same age and that 15 out of 23 children over 8 years of age showed reading retardation, while about $50 \%$ were retarded in number skills.

Del Carlo Giannini and Marcheschi (1959) studied 18 cases of muscular dystrophy, including 7 of the Duchenne-type: 5 of the latter group had a marked reduction in $\mathrm{IQ}$.

More recently Allen and Rodgin (1960) found a mean IQ of 82 in a series of 30 boys with muscular dystrophy, ranging in age from 2 to 23 years. Various standard tests were used and the IQ ranged from 14-117. There were 15 boys with an IQ over 95. There was no correlation between the degree of intellectual impairment and the severity of the physical disability. While they also found evidence for depression of intellectual function related to emotional problems associated with the physical handicaps, they did not think this in itself could explain the intellectual impairment.

Worden and Vignos (1962) made a detailed study of the intelligence in 38 cases of progressive muscular dystrophy. All but one were over the age of 7 . The mean IQ was 83, with a range of 46-134. Only 3 were above 110 , while 26 were below 90 . There was also evidence of special difficulties with reading and mathematics, and the mean educational quotients in these two fields were 83 and 87 respectively. They found no correlation between the IQ and the disability grading of the disease and no evidence of a progressive mental deterioration with advance of the disease. In a comparative study of 27 unaffected sibs of these patients they obtained a mean IQ of 110 and in a series of 16 cases of 'amyotonia congenita' with equivalent or more severe physical handicap, the mean IQ was 118 .

\section{Material and Methods}

This investigation of the intellectual development in progressive muscular dystrophy falls into three parts. 
TABLE

PSYCHOMETRIC ASSESSMENT OF 27 CASES OF MUSCULAR DYSTROPHY CORRELATED WITH CLINICAL DATA

\begin{tabular}{|c|c|c|c|c|c|c|c|}
\hline \multirow{2}{*}{ Case No. } & \multirow{2}{*}{$\begin{array}{c}\text { Chronological } \\
\text { Age (yr.) }\end{array}$} & \multirow{2}{*}{$\underset{(y r .)}{\text { Mental Age }}$} & \multirow{2}{*}{ IQ } & \multirow{2}{*}{$\begin{array}{c}\text { Clinical* } \\
\text { Rating }\end{array}$} & \multicolumn{3}{|c|}{ Motor Milestones (age in months) } \\
\hline & & & & & $\begin{array}{c}\text { Sat } \\
\text { Unsupported }\end{array}$ & $\begin{array}{c}\text { Stood } \\
\text { Unsupported }\end{array}$ & $\begin{array}{l}\text { Walked } \\
\text { Unaided }\end{array}$ \\
\hline $\begin{array}{l}16 \\
4 \\
36 \\
31 \\
43 \\
37 \\
12 \\
20 \\
27 \\
48 \\
45 \\
55 \\
1 \\
28 \\
22 \\
42 \\
33 \\
35 \\
23 \\
15 \\
41 \\
53 \\
40 \\
14 \\
25 \\
32 \\
26\end{array}$ & $\begin{array}{rl}16 & + \\
15 & 2 / 12 \\
12 & 6 / 12 \\
12 & 4 / 12 \\
12 & 2 / 12 \\
16 & 1 / 12 \\
11 & 6 / 12 \\
12 & 7 / 12 \\
9 & 5 / 12 \\
16 & + \\
15 & 10 / 12 \\
14 & 6 / 12 \\
14 & 1 / 12 \\
8 & \\
9 & 9 / 12 \\
9 & 9 / 12 \\
11 & 8 / 12 \\
13 & 2 / 12 \\
15 & 6 / 12 \\
10 & 8 / 12 \\
11 & 3 / 12 \\
16 & + \\
14 & 7 / 12 \\
12 & 8 / 12 \\
12 & 11 / 12 \\
15 & 7 / 12 \\
12 & 11 / 12\end{array}$ & $\begin{array}{cl}17 & 9 / 12 \\
15 & 7 / 12 \\
12 & 7 / 12 \\
12 & 2 / 12 \\
11 & 2 / 12 \\
12 & 2 / 12 \\
8 & 10 / 12 \\
9 & 6 / 12 \\
6 & 10 / 12 \\
10 & 8 / 12 \\
10 & \\
9 & 2 / 12 \\
8 & 10 / 12 \\
5 & 1 / 12 \\
5 & 10 / 12 \\
5 & 10 / 12 \\
6 & 10 / 12 \\
7 & 6 / 12 \\
8 & 4 / 12 \\
6 & 2 / 12 \\
6 & \\
8 & \\
7 & 2 / 12 \\
6 & 6 / 12 \\
6 & 2 / 12 \\
7 & \\
5 & 5 / 12\end{array}$ & $\begin{array}{r}118 \\
103 \\
101 \\
99 \\
92 \\
81 \\
77 \\
76 \\
73 \\
71 \\
67 \\
65 \\
64 \\
64 \\
60 \\
59 \\
59 \\
57 \\
56 \\
55 \\
53 \\
53 \\
51 \\
51 \\
48 \\
47 \\
42\end{array}$ & 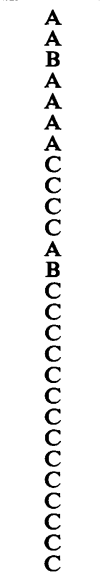 & $\begin{array}{r}9 \\
4 \\
9 \\
5 \\
8 \\
9 \\
9 \\
9 \\
7 \\
7 \\
12 \\
8 \\
12 \\
8 \\
9 \\
12 \\
6 \\
12 \\
? \\
8 \\
12 \\
12 \\
15 \\
9 \\
? \\
8 \\
9\end{array}$ & $\begin{array}{r}12 \\
10 \\
16 \\
10 \\
13 \\
20 \\
11 \\
12 \\
15 \\
12 \\
18 \\
14 \\
18 \\
18 \\
20 \\
18 \\
12 \\
18 \\
? \\
11 \\
24 \\
? \\
24 \\
11 \\
? \\
15 \\
24\end{array}$ & $\begin{array}{l}12 \\
15 \\
24 \\
18 \\
16 \\
24 \\
12 \\
24 \\
17 \\
18 \\
24 \\
16 \\
18 \\
24 \\
48 \\
20 \\
18 \\
30 \\
24 \\
12 \\
27 \\
18 \\
30 \\
12 \\
24 \\
24 \\
24\end{array}$ \\
\hline
\end{tabular}

* A, normal intelligence; B, probably retarded; C, retarded.

Part I: A clinical assessment of intelligence in the course of a comprehensive study of 65 patients with Duchennetype muscular dystrophy (Dubowitz, 1960). This was based on the clinical history of milestones, which was obtained from the parents, and on the clinical impression of intelligence assessed in a fairly empirical way on the basis of simple reading, writing, arithmetical, and general knowledge tests appropriate to the age. On this basis the children were divided into three groups: A, normal intelligence; $\mathbf{B}$, possibly retarded; and $\mathbf{C}$, definitely retarded.

Part II: A psychometric assessment of 27 long-term in-patients by the Terman-Merrill revision of the StanfordBinet test (form L). All these children had attended the hospital school for at least 6 months.

Part III: Three patients, who were diagnosed early, have been studied prospectively. Various tests of intellectual as well as motor and manipulative abilities were performed at frequent intervals. Comparative studies in unaffected sibs were also done along similar lines. These three patients will be described in detail.

\section{Results}

Part I. Of the 65 patients in this study, 63 were male and 2 were female. Their ages ranged from 3-19 years.

Milestones. An arbitrary upper limit of normal for sitting without support, standing unsupported, and walking unaided, was taken as 9 months, 14 months, and 18 months, respectively. A delay in walking plus one of the other motor milestones was considered a delay, and a delay in walking alone or in both sitting and standing a doubtful delay.

On this basis the motor milestones were normal in 27 cases, there was a delay in 28 cases, and a doubtful delay in 9 . In one instance no information was available.

Of the 34 children who were not walking by 18 months, 29 did not walk till the age of 2 years or over.

Clinical Assessment. 30 children (46\%) were considered to be of average or above average intelligence (category A), 21 (32\%) retarded (category $\mathrm{C})$, and 14 (22\%) possibly retarded (category B).

Of the 30 children in category A, 18 had normal motor milestones, 9 had delayed milestones, and 3 possibly delayed milestones. Of the 21 cases in category $\mathrm{C}, 5$ had normal milestones, 11 were delayed, and 4 doubtfully delayed. In the intermediate category B, 4 had normal milestones, 8 were delayed, and 2 doubtfully delayed.

Part II. The results of the psychometric testing of the 27 children are given in the Table. Ten patients had an IQ above $70(37 \%) ; 14(52 \%)$ had an IQ score of between 50 and 70 and $3(11 \%)$ below 50 . The clinical rating correlated fairly well with the IQ assessment in the majority of these cases. With regard to the motor milestones, of the 10 patients 
with an IQ over 70, 7 were walking at the age of 18 months, while of the 17 with an IQ of under 70 only 5 were able to walk by that age. Using the same criteria as in Part I above, the motor milestones were considered to be normal in 7 of the 10 patients with an IQ above 70 , delayed in 2 , and doubtfully delayed in 1. In the group with an IQ less than 70, 4 had normal milestones, 10 had delay, and 3 doubtful delay.

Part III. On the basis of the detailed developmental history and the repeated assessment of various intellectual, manipulative, and other abilities, it was concluded that all three children had intellectual impairment out of proportion to their physical handicap. Detailed case histories are included in the appendix.

The degree of intellectual impairment in Case 3 was less marked than in the other two cases.

Serial examination in Case 1 suggested a deterioration in intellectual function, in that certain previously acquired skills were subsequently lost. Moreover in other intellectual spheres this child was fairly static and not advancing at a normal rate. This would imply a fall in IQ with increasing age. In Case 2, the history suggested that some of the child's previous skills, such as counting, had deteriorated.

\section{Discussion}

There are numerous difficulties in trying to assess intelligence in children with severe physical handicap. Many of the standard tests for older children are weighted for general knowledge and experience which may be limited because of physical disabilities. In infancy many of the tests depend on manipulation and co-ordination which can be affected by muscular weakness.

It is deceptive to assess intelligence on clinical impression, because the physically handicapped child may become introverted and apathetic and thus give the impression of a lower intelligence than he in fact has.

In spite of the criticism that may be levelled at each approach, there has been a fairly uniform pattern of results and a number of interesting correlations have become apparent. In most children, the clinical assessment correlated fairly well with the psychometric testing. In both less than half were in the normal range.

There was a significant correlation between delayed motor milestones and intellectual retardation In the children judged to have a normal intelligence by psychometric testing $70 \%$ had normal milestones, while in those judged to be subnormal under $25 \%$ had normal milestones. Similarly in the clinical assessment there was a significantly higher proportion of children with normal milestones in category A (normal intelligence) than in category B or C.

A positive family history was much less frequent in the cases of normal intelligence than in the retarded ones. Of 10 patients with IQ above 70 on psychometric testing, only 2 had a positive family history (Table, Cases 27 and 48). Of the 17 with IQ below 70,10 had a positive history. In category $A$ (normal intelligence) on clinical assessment, the family history was positive in 4 (all definite sex-linked recessive), negative in 24 , and the 2 affected sisters had consanguineous parents, indicating an autosomal recessive inheritance. In category $C, 10$ had a positive family history and 11 a negative one, while in category $B$ the figures were 8 and 6 respectively.

Why are some children with typical Duchennetype muscular dystrophy of grammar school intelligence, while others, with equal muscular involvement, are ineducable? The higher incidence of negative family histories in the more intelligent group suggests that a larger proportion of these may have an autosomal recessive rather than a sex-linked recessive inheritance with a different disease pattern.

An alternative explanation is that separate genes are responsible for the muscular dystrophy and the intellectual impairment. Perhaps under these circumstances one would expect to find intellectual impairment without muscular dystrophy in some sibs, but this was not the case.

The possibility of intellectual impairment being a sequel of the physical handicap is not borne out by the detailed studies of the three early cases. The severe intellectual impairment in all three was out of proportion to the physical disability. In 2 of them, younger sibs had already overtaken them in intellectual development.

In this context, it is also of interest that the intelligence was normal in 12 patients with a slowly progressive form of infantile muscular atrophy where the onset was usually earlier and physical disability more severe than muscular dystrophy (Dubowitz, 1964).

The most likely explanation for the intellectual impairment in progressive muscular dystrophy is a biochemical abnormality affecting the metabolism of brain as well as muscle. The apparent absence of progression of the intellectual impairment may be due to maximal involvement in early life, when the brain is most vulnerable, and an imperceptible deterioration thereafter. In those with normal intelligence, the initial onset may be less acute and severe, thus also explaining the higher incidence of normal motor milestones in this group. 


\section{Conclusions}

Severe intellectual impairment is a commonly associated feature of progressive muscular dystrophy of the Duchenne-type. It may already be present before the onset of the severe physical disability. It is probably an integral part of the disease process, and any theory of the aetiology of the disease should take this into account. It may, therefore, not be entirely accurate to look upon muscular dystrophy as a disease confined to voluntary muscle.

It is difficult to explain why some children should have a normal intelligence, in contrast to others who are severely retarded, in spite of similar severity of muscular involvement. A possible explanation in some of these cases is a different gene inherited by an autosomal recessive rather than a sex-linked recessive mechanism, or that separate genes are responsible for the intellectual impairment and the muscular involvement. A more likely explanation is a single biochemical lesion affecting brain and muscle, but with less acute onset in those with normal intelligence. Alternatively, a product of the muscle destruction may affect the developing brain.

I wish to thank Professor R. S. Illingworth for his help and advice, Dr. David Lawson for the facilities he afforded me at Queen Mary's Hospital for Children, Carshalton, and Miss E. J. Shearn for the psychometric tests.

This work has been supported by grants from the Muscular Dystrophy Group of Great Britain and the Sheffield University Research Fund.

\section{REFERENCES}

Allen, J. E., and Rodgin, D. W. (1960). Mental retardation in association with progressive muscular dystrophy. Amer. J. Dis. Child., 100, 208.

Del Carlo Giannini, G., and Marcheschi, M. (1959). Sui disturbi psichici nella distrofia muscolare primitiva. Sist. nerv., 11, 461.

Dubowitz, V. (1960). Progressive Muscular Dystrophy in Childhood. M.D. Thesis, University of Cape Town.

- (1964). Infantile muscular atrophy. A progressive study with particular reference to a slowly progressive variety. Brain, 87, 707.

Duchenne, G. B. (1872). De l'Electrisation Localisée et de Son Application à la Pathologie et à la Thérapeutique, 3rd ed. Bailliere, Paris.

Erb, W. (1891). Dystrophia muscularis progressiva. Klinische und pathologisch-anatomische studien. Dtsch.Z. Nervenheilk., 1, 13, 173.

Gowers, W. R. (1879). Pseudo-hypertrophic Muscular Paralysis. A Clinical Lecture. Churchill, London.

Morrow, R. S., and Cohen, J. (1954). The psycho-social factors in muscular dystrophy. J. Child. Psychiat. (N.Y.), 3, 70.

Truitt, C. J. (1955). Personal and social adjustments of children with muscular dystrophy. Amer. J. phys. Med., 34, 124.

Walton, J. N., and Nattrass, F. J. (1954). On the classification, natural history and treatment of the myopathies. Brain, 77, 169 .

Worden, D. K., and Vignos, P. J., Jr. (1962). Intellectual function in childhood progressive muscular dystrophy. Pediatrics, 29, 968.
Appendix

Case 1. This boy, born October 18,1960 , was referred on June 14,1963 , at the age of $2 \frac{3}{4}$, because his father thought that 'he had no sense'.

He did not sit unsupported till 10 months. He stood with support at about 16 months and on his own at 18 months. He walked without support at about 20 months. At $2 \frac{3}{4}$ he was still not very stable on his feet and fell frequently. He had slight difficulty in getting up from the floor. He was not able to run, skip, or jump and had difficulty in stepping on to a pavement or climbing steps. He had no difficulty with chewing or swallowing. He did not learn to drink from a cup until the age of 2 . He was able to feed himself with a spoon but still messed a lot. He had no bowel or bladder control.

He was very late in speaking and had only recently acquired the single words-'daddy, mummy, van, and baby'. He made no attempt to put words together.

He did not imitate any activities of his parents or sibs. He was not able to dress or undress himself. He did not obey commands or bring objects he was asked for. His mother thought he needed more coaxing and was less interested in things than before, but there was no obvious regression in intellectual activity. However, he did seem fairly static and improvement in intellectual function was barely perceptible.

Clinical Examination. He walked with a slight waddle, supported a hand on the knee when getting up from the prone, and could be diagnosed as an early muscular dystrophy on clinical grounds.

He had a mature two-finger grasp for small objects. He was able to match two cubes and make a tower of 3 cubes. He made no attempt to make a train or bridge with cubes. He was unable to place the blocks in a simple formboard, but piled them on top of each other. He did not copy a line, but only scribbled with a pencil. His grasp of the pencil was immature. He turned a few pages of a book at a time, and was unable to turn them singly. He did not point to pictures.

On the basis of the history and clinical assessment his intellectual development was considered to be less than that of an 18-month-old child in all spheres.

The diagnosis of muscular dystrophy was confirmed by the raised serum enzymes levels (SGOT 220 units, SGPT 292 units, aldolase 154 units, and creatine kinase 570 $\mu \mathrm{M} / \mathrm{ml} . / \mathrm{hr}$.); and the typical histological features on muscle biopsy.

FAMILY History. The mother has a brother suffering from muscular dystrophy, and an affected son by a previous husband.

SiBs. His 15 -month-old male sib cruised at 10 months and was just about walking without support. His speech was much more advanced; he had a vocabulary of at least 10 words and was putting words together. He was able to feed himself with a cup and spoon from the age of 11 months.

On detailed assessment his intelligence was judged to be normal for his age and in many respects in advance of his affected brother. 
An older male sib, aged $4 \frac{1}{2}$, walked at $10 \frac{1}{2}$ months. His intelligence was normal on assessment.

Follow-up of PAtient. One month later there was no change in his speech, or general intellectual and manipulative abilities, though he did manage to build a tower of 8 cubes.

In November 1963, aged 3 years, he was saying more words, but not putting two words together. He was able to take off his shoes. He placed a circle in the simple formboards, and could adapt. He was only able to build a tower of 3 bricks.

In December 1963, there were no new achievements.

In January 1964, he was saying more single words, but not putting words together yet. He placed the circle in the simple formboard and could adapt. He made a tower of two bricks only. He refused to page a book. He could not copy pencil strokes, and did not identify pictures. He had not yet acquired sphincter control.

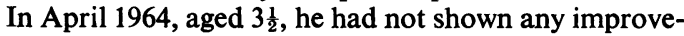
ment in intelligence. Mother said he was not able to say as many words as before and had not acquired any new ones. He did not help with dressing or undressing. He only obeyed an occasional command. He was not yet using a potty. Often when asked to do something he stared as if he did not understand. He tended to be introverted, would not play with other children, and was content to sit and play with his cars. He was able to make a tower of 4 cubes only and they were poorly aligned. He would not place the circle in the simple formboard. He was unable to copy a straight line or circle, and the only command he obeyed was 'open the door'.

There was very little change in his motor disability, but there appeared to be a deterioration in his intellectual capacity.

Case 2. This boy, born on March 22, 1957, was first seen in November 1962, aged 5 years and 8 months. He had never been an active child. He sat without support at 11 months, stood up at 18 months, shuffled on his bottom at 20 months and walked at 26 months. He had a waddling gait and had difficulty with running and climbing stairs.

He did not say single words until 18 months and started to put words together at about $2 \frac{1}{2}$ years. He seemed to have no power of concentration and his mind seemed to wander.

He had recently started school and was not making any progress. He could not write or draw and only scribbled. At one time he was counting up to 10 , but when examined he could only count to 2 and then repeat it.

ExAmination. In November 1962 he showed the typical clinical features of muscular dystrophy. He was able to obey single commands but not multiple ones. He could not copy any geometric forms. In repeating sentences he only said the last one or two words. He did not know his age. He made a tower of 6 cubes and nearly managed to make a bridge with three cubes. He completed the Goddard formboard test in 90,70 , and 60 seconds, respectively, on three successive occasions. With the Goodenough 'draw a man' test, he did not score at all.

His intelligence was judged to be below the 3-year level in all spheres.

The diagnosis of muscular dystrophy was confirmed by abnormally high levels of serum enzymes, namely, SGPT 580, SGOT 318, aldolase 208 units, and creatine kinase $800 \mu \mathrm{M} / \mathrm{ml}$./hr.

FAMily History. The mother's twin sister has an affected child (Case 3 below), and three affected cousins (Cases 26, 27, and 28) have been assessed previously.

SiB. A younger sib, aged 19 months, sat unsupported at 8 months, stood on his own at 10 months, crawled at 9 months, and walked at 14 months. He was saying single words from 8 months, and at 19 months was putting 2 or 3 words together. He was able to make a tower of 4 cubes, and placed the circle and square in the simple formboard. His intelligence was regarded as normal.

Follow-up of Patient. Three months later there was little change. By July 1963 there had been some improvement in his speech and he was saying more words. He was able to copy a square and a cross, but not a circle. He made a tower of 9 cubes without difficulty.

After three trials he was able to repeat 3 digits. He was still only able to remember one command. He was unable to say any nursery rhymes and he only repeated the first and last words of sentences given to him. On three attempts the best time for the Goddard formboard was 46 seconds. He made no score on the Goodenough 'draw a man' test.

In October 1963 his performance was about the same. In February 1964, aged 6 years and 11 months, there was some further improvement in his speech, and he was making full sentences. At school he was in a class of average age $5 \frac{1}{2}$ to 6 years, and was not showing much progress. He was unable to do sums or to write. He was still unable to count beyond 2 . He repeated 2 digits correctly on 3 successive attempts, but was unable to repeat 3 digits on 3 trials. He was unable to name coins. He still left out parts of sentences he was asked to repeat. He could point to parts of his anatomy and knew left from right. His best time with the Goddard formboard was 55 seconds.

He made a tower of 10 cubes without difficulty, a bridge spontaneously, and a gate after being shown. He was readily distracted from what he was doing. With the Goodenough 'draw a man' test he scored at the 4-year level.

There had been some decline in his motor power, but he was still able to walk well and to get up after falling. He had great difficulty in climbing steps. His intellectual development was still below the 4-year level.

In contrast his sib, at 3 years, was able to make a tower of 10 cubes, to repeat 2 digits in each of the three trials, and 3 digits in 1 out of 3 trials. He was speaking in full sentences and his speech was more advanced than his older brother. 
Case 3. This is a cousin of Case 2, born on April 23, 1961. He was first seen in November 1962, aged 19 months. He had smiled at 6 weeks and cooed at the same age. He made no attempt to roll from prone to supine or vice versa. He sat unsupported at 9 months. He shuffled on his bottom from the age of 13 months. At 19 months he could stand with support, but not unaided, and was not cruising. He started casting at 1 year but did not wave bye-bye till 16 months. He said single words with meaning from about 18 months, but was was not putting words together.

EXAmination. He stood well with support and walked with two hands held. He had a mature grasp and instant finger thumb apposition. He was uncooperative with any further tests.

In January 1963, aged 21 months, he was cruising with the furniture. He was putting words together. He built a tower of 2 cubes but was unable to place the blocks in a simple formboard. He seemed more alert and interested than previously.
At 22 months he was able to pull up into a standing posture, and started walking at the age of 2 . He went upstairs on all fours and down on his bottom.

At 2 years and 10 months, he was putting 3 or 4 words into sentences. He pointed to objects in a book, but could not repeat nursery rhymes. He was able to feed himself with a spoon. He had bladder control by day. He used a pot when given one, but did not ask for it.

He made a tower of 5 cubes and aligned them into a train. He placed the circle in the simple formboard, but had difficulty in adapting. He was unable to copy a line or a circle, but only scribbled. He could point to parts of his face and he named objects in a book.

Clinically there were signs of early muscular dystrophy. The diagnosis was confirmed by a raised serum creatine kinase level of $680 \mu \mathrm{M} / \mathrm{ml} . / \mathrm{hr}$. and the pathological changes on muscle biopsy.

His general intellectual performance was considered to be less than the 2-year level.

His sister aged 5 years was of normal intelligence in all respects. 